\title{
The Effects Of Casuarina Bark On Lipid Profile And Random Blood Sugar Level In Albino Rats
}

\author{
Aloh Godwin Sunday ${ }^{1}$,Obeagu Emmanuel Ifeanyi ${ }^{2}$, Umechukwu Chioma \\ Eucharia $^{3}$ \\ 1.Lecturer,Department of Biochemistry,Michael Okpara University of Agriculture,Umudike,Abia State,Nigeria. \\ 2.Diagnostic Laboratory Unit,University Health Services Department, Michael Okpara University of \\ Agriculture,Umudike,Abia State,Nigeria. \\ 3.Department of Biochemistry,Ebonyi State University,Abakaliki,Nigeria.
}

\begin{abstract}
The effect of Casuarina equisetifolia bark incorporated into rat feed at 10-40\% on the lipid profiles and blood sugar of albino rats was investigated. The rats were fed ad lib for 21 days. The parameters studied were triacylglycerol (TGL), total cholesterol (TC), total lipid (TL), phospholipids (PHOS), high-density lipoprotein (HDL) and random blood sugar (RBS). Their means were subjected to a $t$-Test at $P<0.05$. There was no significant change $(P>0.05)$ in the TGL levels of all the rats, including the control, as they all range between 0.18-0.22( $\mathrm{mg} / \mathrm{dl})$. The effects on TC and TL were irregular as they did not display any dose dependence. The mean plasma PHOS levels did not change significantly $(P>0.05)$ between the control and the rats fed on $10 \%$ feed $(0.19 \pm 0.00$ vs $0.18 \pm 0.00 \mathrm{mg} / \mathrm{dl})$, was significantly lowered $(P<0.05)$ at $20-40 \%$ feed content but did not change significantly $(P>0.05)$ in the rats maintained on the feeds with the $20-40 \%$ bark contents. The mean $H D L$ level rose, although insignificantly $(P>0.05)$ with the percentage contents of the bark in the feeds; by implication, the low-density lipoprotein ( $L D L)$ was decreasing with the increase in the bark contents of the feeds-cardioprotective. The RBS also decreased as the percentage bark contents of the feeds increased, indication that it could have anti-diabetic properties.
\end{abstract}

Keywords: Casuarina equisetifolia bark,Triacylglycerol,Total cholesterol,Total lipid,phospholipid,high density lipprotein,random blood sugar.

\section{Introduction}

Casuarina equisetifolia L. (Casuarinacae) is an evergreen tree to $25 \mathrm{~m}$ high with drooping braches and needle-like branchlets. The Bark is light greyish-brown, smooth on young trunks, rough thick, furrowed and flaking into oblong pieces on older trees; inners bark reddish or deep dirty brown, astringent (Cambine and Ash, 1994). Common along the beaches, rocky coats, limestone outcroppings, dry hillsides and open forests in both wet and dry zones from sea-level to mid montane. Native to South-East Asia, Australia and Polynesia. It is also cultivated as an ornamental, for wind-breaks, or as a medical plant in some tropical countries in the South Pacific.

The chief chemical constituents include Caffeic acid; chlorogenic acid; d-gallocatechin; ellagic acid; prodelphinidin; propelargonidin; quercetin; rutin. It is also accounted to contain $98 \%$ of asparagine and glutamine of the total amino acid in the nodules. The bark contains $10 \%$ catchol tannin, the root $15 \%$.

Phytosterol from the leaves of the plant shows antibacterial activity, hypoglycaemic, antifungal, molluscidal, cytotoxic. In Tahiti, the plants are used to treat nervous disorders, diarrhoea and gonorrhoea (Whistler, 1992). Tongans use it to treat cough, ulcers, stomach aches and constipation. Dysuria and menorrhagia are treated with an infusion of the bark. An infusion of the bark, in Tonga is used as an emetic to treat throat infections.

Cardiovascular system refers to the passage through which blood flows- the heart, arteries, veins and capillaries. It is the portion of the circulatory system that includes the heart and blood vessels. It moves the blood between the body cells and organs of the integumentary, digestive, respiratory and urinary systems that communicate with the external environment.

Cardiovascular disease is a class of disease that involves the heart or blood vessels (arteries, capillaries and veins). Cardiovascular disease refers to any disease that affects the cardiovascular system, principally cardiac disease like coronary heart disease. The causes of cardiovascular disease are diverse but atherosclerosis and hypertension are the most common. (Burtis et al., 2008).

Lipid profile is used to diagnose, detect, evaluate and distinguish cardiovascular disease or injuries. Lipid profile is a collective term for tests carried out for total cholesterol, high-density lipoproteins, low-density lipoproteins and triglycerides. An extended lipid profile may include very low-density lipoproteins. This is used to identify hyperlipidemia (various disturbances of cholesterol and triglyceride levels), many forms of which are recognized risk factors for cardiovascular disease and sometimes pancreatitis (Sagara et al., 2008). 


\section{Aims and objectives}

The sole aim of this project is to determine the effects of bark of Casuarinaequisetifoliaplant on cardiovascular by monitoring lipid profile and blood glucose level of albino rats treated with it

\section{Biological Materials}

\section{Materials And Method}

Albino rats

Casuarinasequisetifolia plant (Bark)

\section{METHODS}

\section{Collection of samples}

Collection of plants Ebonyi State.

The Casuarina equisetifolia plant (Bark) was collected from the people's club garden Abakalili,

\section{Collection of Albino rats}

The albino rats were purchased from the zoology department of University of Nigeria (UNN). They were fifteen (15) in number, which was later kept in biochemistry department animal house.

\section{Preparation of plant sample}

The casuarinas bark which has been kept under room temperature for about 2 weeks grinded with a blender into a powder form.

\section{Animal handling and treatment}

The animals were kept in five cages. Three animals per cage and were labelled properly, control, Group 1 - Group 4. For control animals poultry food and water was given to them, 1, 2, 3 and 4 were given 10\%, 20\%, $30 \%$ and $40 \%$ of the compounded feed. The feed was compounded as follows:

$10 \%$ of feed $-900 \mathrm{~g}$ of poultry food $+100 \mathrm{~g}$ of powdered casuarina bark.

$20 \%$ of feed $-800 \mathrm{~g}$ of poultry food $+200 \mathrm{~g}$ of powdered casuarina bark.

$30 \%$ of feed $-700 \mathrm{~g}$ of poultry food $+300 \mathrm{~g}$ of powdered casuarina bark.

$40 \%$ of feed $-600 \mathrm{~g}$ of poultry food $+400 \mathrm{~g}$ of powdered casuarina bark.

\section{Collection of blood samples from the animals}

The blood sample was collected from the heart after being anaesthetized. The blood was dispensed into a sterile specimen bottle and were appropriately labelled and allowed to clot before centrifuged. The supernatant (serum) was collected using micropipette.

\section{Determination of lipid profile}

Estimation of total serum cholesterol (Ochei and Kalhatkar, 2007).

Principle: in the presence of excess acid such as phosphoric acid and ferric $\left(\mathrm{Fe}^{3+}\right)$ ions, cholesterol is oxidized to disulphuric acid which is reddish purple in colour (Salkoroske reaction). It is read spectrophometically at $560 \mathrm{~nm}$ (green yellow filter).

Specimen: Serum after 12 hours fast.

Procedure: Using ferric reagent, cholesterol standard $(250 \mathrm{mg} / \mathrm{dl})$.

- The serum is diluted with water in the ration of $1: 20(0.1 \mathrm{ml}$ of serum $+1.9 \mathrm{ml}$ distilled water $)$

- Cholesterol standard is diluted with glacial acetic acid in the ratio of 1:20.

- The three test tubes were shook for 10 seconds to mix the contents properly

- The test tubes were placed immediately in a boiling water baht for exactly 90 seconds.

- $\quad$ They were cooled in a running tap water for 5 minutes.

- Absorbances were read for all the test tubes (mixtures) using spectrophometer at 560nm

Where $250=$ concentration of standard

The values were in $\mathrm{mg} / \mathrm{dl}$ but can be converted to $\mathrm{mmol} / \mathrm{L}$ by multiplying by 0.0259 .

\section{ESTIMATION OF SERUM HDL CHOLESTEROL (OCHEI AND KALHATKAR, 2007).}

Principle: Chylomicrons, VLDL and LDL are precipitated by phosphotungstic acid in the presence of magnesium ions, leaving HDL in solution, which is read using spectrophometer.

Procedure: Using phosphotungstic acid reagent, magnesium chloride solution colour reagent concentrated sulphuric acid, cholesterol standard. 
- $\quad$ Two test tubes were set up and labelled test and standard.

- $\quad 1 \mathrm{ml}$ of serum was added to the test using micropipette.

- $\quad 0.1 \mathrm{ml}$ of phosphotungstic acid reagent was added to both test tubes and mixed well

- $\quad 0.05 \mathrm{ml}$ magnesium chloride solution was also added immediately and stirred.

- After stirring, the mixture was centrifuged using a centrifuge at $2500 \mathrm{rpm}$ for 30 minutes.

- The supernatants were transferred to another test tube using Pasteur pipette, then absorbance was read using spectrophometer at 560nm.

The values were in $\mathrm{mg} / \mathrm{dl}$ but can be converted to mmol/L by multiplying by 0.0259 .

Estimation of serum Triacylglycerol (OCHEI AND KALHATKAR, 2007)

Procedure: Using colour reagent (mixture of solution A and solution B) and triglyceride standard.

- $\quad$ Three tubes were set up and properly labelled test, standard and blank.

- $\quad 3.0 \mathrm{ml}$ of colour reagent was added to the three test tubes.

- $\quad 0.03 \mathrm{ml}$ of serum was added to the test using micropipette while $0.03 \mathrm{ml}$ of triglyceride and distilled water was added to the standard and blank respectively.

- The three test tubes were shook well and the mixture mixed well then allowed/ incubated at $37^{\circ} \mathrm{C}$ for 15 minutes in a water bath.

- $\quad$ Absorbance was obtained using spectrophometer at $42 \mathrm{~nm}$ using blank to zero.

The values were in $\mathrm{mg} / \mathrm{dl}$ but can be converted to $\mathrm{mmol} / \mathrm{L}$ by multiplying by 0.0113 .

Estimation of total lipid (Burtis et al., 2008)

Procedure: Using trichloroacetic acid, 0.6 in aqueous solution of ammonium molybdate reagent concentrated perchloric acid, reducing agent.

- $\quad 0.2 \mathrm{ml}$ of blood serum and $2.8 \mathrm{ml}$ of distilled water was added to a sample test tube, $3 \mathrm{ml}$ of the distilled water was added to a control test tube

- $\quad 3 \mathrm{ml}$ of trichloroacetic acid was added to each test tube and the contents were mixed by shaking.

- $\quad$ The sample solution was allowed centrifuge for 15 minutes at $3000 \mathrm{rpm}$.

- The supernatant liquid was decanted and placed in the test tube upside down on a piece of filter paper to let the residual liquid flow out.

- $\quad 1 \mathrm{ml}$ of concentrated perchloric acid was poured into both test tubes and two glass beads placed in each and the contents mixed.

- The test tubes were placed in the sand bath at $180^{\circ} \mathrm{C}$ for $20-30$ minutes to hydrolyze the contents (until the solution decolorize).

- The test tubes are allowed to cool under room temperature and then $3 \mathrm{ml}$ of distilled water. $1 \mathrm{ml}$ of ammonium molybdate reagent and $2 \mathrm{ml}$ of freshly prepared reducing agent was added.

- The contents were mixed thoroughly and allowed to stand for 10 minutes at room temperature.

- The absorbance of the sample solution was measured against control solution on the photocalorimeter at $630 \mathrm{~nm}$.

- The total phospholipids concentration $\mathrm{x}(\mathrm{g} / \mathrm{litre})$ in blood serum is calculated by making use of the formular

Where $\mathrm{m}$ is the mass of inorganic phosphate in the sample solution $\mathbf{m g}$; 5000 ; is the sealing factor for conversion to per litre blood serum; 10 is the sealing factor for milligram to gram conversion. 25; is the sealing factor (Lipid phosphorus accounts for $4 \%$ of relative molecular mass of phospholipids) the values were in ( $\mathrm{g} / \mathrm{litre}$ ) but can be converted to $\mathrm{mmol} / \mathrm{litre}$ by multiplying by 0.323 .

\section{Estimation of blood sugar}

Copper-Reaction Method (Renschler et al., 2005)

Procedure: Using sodium tungstate (10\%), 2/3N sulphuric acid, Alkaline copper tartrate reagent, phosphomolybdic acid reagent, stock glucose standard solution $(1 \mathrm{~g} / \mathrm{dl})$, working glucose standard solution $(10 \mathrm{mg} / \mathrm{dl})$.

- $\quad 0.1 \mathrm{ml}$ of serum and $7.0 \mathrm{ml}$ of distilled water are mixed then $1.0 \mathrm{ml}$ of $2 / 3 \mathrm{~N} \mathrm{H}_{2} \mathrm{SO}_{4}$ was added and allowed to stand for 5 minutes at room temperature.

- It was filtered using whatman No. 1 filter paper.

- $\quad$ Three test tubes were set up and properly labelled test, blank and standard.

- $\quad 1.0 \mathrm{ml}$ of the distilled water was added to blank.

- $\quad 1.0 \mathrm{ml}$ of working standard was added to standard.

- $\quad 1.0 \mathrm{ml}$ of supernatant was added to the test tube.

- $\quad 1.0 \mathrm{ml}$ of alkaline copper tartrate was added to the blank, standard and test.

- $\quad$ The test tubes were placed in boiling water bath for 10 minutes 
- $\quad 1.0 \mathrm{ml}$ of phosphomolybdic acid reagent was added to each test tube and cooled.

- The absorbance was read at $680 \mathrm{~nm}$.

\section{Statistical Analysis}

The results obtained were subjected to statistical analysis using ANOVA

\section{Results}

Table 4.1: The results shows the mean lipid and sugar levels of rats after 21 days of feeding with Casuarina compounded feeds.

\begin{tabular}{|l|l|l|l|l|l|l|l|}
\hline & GROUP & $\begin{array}{l}\text { TGL } \\
(\mathbf{m g} / \mathbf{d l})\end{array}$ & TC(mg/dl) & TL(mg/dl) & PHOS(mg/dl) & HDL(mg/dl) & RBS(mg/dl) \\
\hline 1. & Control & $0.218 \pm 0.002^{\mathrm{a}}$ & $0.065 \pm 0.015^{\mathrm{b}}$ & $0.037 \pm 0.020^{\mathrm{a}}$ & $0.192 \pm 0.003^{\mathrm{a}}$ & $0.002 \pm 0.002^{\mathrm{b}}$ & $0.406 \pm 0.046^{\mathrm{a}}$ \\
\hline 2. & $10 \%$ feed & $0.215 \pm 0.004^{\mathrm{a}}$ & $0.085 \pm 0.007^{\mathrm{b}}$ & $0.029 \pm 0.001^{\mathrm{a}}$ & $0.180 \pm 0.004^{\mathrm{b}}$ & $0.003 \pm 0.001^{\mathrm{b}}$ & $0.154 \pm 0.000^{\mathrm{c}}$ \\
\hline 3. & $20 \%$ feed & $0.219 \pm 0.001^{\mathrm{a}}$ & - & $0.021 \pm 0.019^{\mathrm{a}}$ & $0.170 \pm 0.001^{\mathrm{c}}$ & $0.010 \pm 0.001^{\mathrm{b}}$ & $0.123 \pm 0.001^{\mathrm{c}}$ \\
\hline 4. & $30 \%$ feed & $0.183 \pm 0.060^{\mathrm{a}}$ & $0.074 \pm 0.003^{\mathrm{a}}$ & $0.020 \pm 0.010^{\mathrm{a}}$ & $0.169 \pm 0.001^{\mathrm{c}}$ & $0.013 \pm 0.001^{\mathrm{a}}$ & $0.119 \pm 0.000^{\mathrm{c}}$ \\
\hline 5. & $40 \%$ feed & $0.222 \pm 0.016^{\mathrm{a}}$ & $0.087 \pm 0.009^{\mathrm{a}}$ & $0.031 \pm 0.015^{\mathrm{c}}$ & $0.170 \pm 0.001^{\mathrm{c}}$ & $0.002 \pm 0.000^{\mathrm{b}}$ & $0.199 \pm 0.001^{\mathrm{b}}$ \\
\hline
\end{tabular}

NOTE: Means with the same letter are not significantly different

KEY

TGI: Triacylglycerol

TC: $\quad$ Total choleaterol

PHOS: Phospholipids

HDL: High Density Lipoproteins

RBS: $\quad$ Random Blood sugar

\section{Discussion}

Cholesterol is an essential substance involved in many cellular functions, including the maintenance of membrane fluidity, production of vitamin D on the surface of the skin, production of hormones and possibly helping cell connections in the brain (Daniels et al., 2009). It is of vital necessity that the body cells should have adequate supply of cholesterol. However, when cholesterol levels rise in the blood, they can deleterious consequences; in particular, cholesterol has generated considerable notoriety for its causative role in atherosclerosis, the leading cause of death in developed countries around the world (Stamler et al., 2000). Great efforts have been put into reducing the risk of cardiovascular diseases through the regulation of cholesterol, traditional plant remedies have been used in the treatment of illness (Akhtar and Ali, 2004) but only few have been evaluated scientifically. Therefore, the effects of the diet preparations of bark of Casuarina equisetifolia on the lipid profile of rats were studied and compared.

The analysis of lipid profile reviewed significantly high levels $(\mathrm{P}<0.005)$ of total cholesterol, no significant difference in triacylglycerol and total lipid $(\mathrm{P}>0.005)$. The biochemical mechanism responsible for this is an interesting subject for further research, since studies made on the ethanolic extract of the plant shows it has anti-hyperlipidaemic effect (Bucholtz et al., 1997)

Phospholipids are majorly components of all cell membranes which are usually found with cholesterol molecules (Choi et al., 2005). There is no significant change in phospholipid level between the control and the rats fed on $10 \%$, but was significantly lowered $(\mathrm{P}<0.05)$, at $20-40 \%$ feed content following the administration of the compounded Casuarina equisetifolia bark is an indication that the plant extract may possess antihyperlipidemic properties and this may help reduce the incidence of cardiovascular diseases like atherosclerosis and hypertension.

Also there was increase in HDL - cholesterol level although insignificant in the Casuarina equiserifolia fed rats compared to the control. Although in the past, an increase in the serum total cholesterol level is associated with increased risk of arherosclerosis, however, recent reports indicated that the LDL/HDL ratio is a stronger index of atherogenicity of the lipoproteins rather than the lipid profile of the individual lipoprotein fraction i.e the lower the ratio, the less atherogenic the lipoprotein profile is thought to be.

The significant reduction observed in the blood glucose level $(\mathrm{P}<0.005)$ following the administration of the compounded diet is an indication that the plant possess anti-diabetic effect. Earlier studies made on the extract of the plant shows that some chemical constituents of the plant are responsible for its anti-diabetic effect.

\section{Conclusion}

Based on the result obtained in this research, consumption of the Casuarina esquisetifolia (Bark) could be beneficial to people at high risk of cardiovascular disease. More investigations are required in the actual mechanism of Casuarina esquisetifolia (Bark) in the studied parameter. 


\section{Reference}

[1]. Akhtar, M. S. and Ali, M. R. (2004). Study of Antidiabetic Effect Of A Compound Medicinal Plant Prescription In Normal And Diabetic Rabbits. Journal of Pakistan Medical Association. 34: 239-244.

[2]. Bucholtz, G. A, Hansel, A. E., Lockey, R. F., Serbousek, D. G and Wunderlin, R. P. (1997). Australian Pine (Casuarina Equisetifolia) Pollen As An Aero Allergen. Annual Allergy, 59(1): 52-56.

[3]. Burtis, C. A., Ashwood, E. R and Bruns, O. E. (2008). Fundamentals of Clinical Chemistry. 6yh Edition, Everbest, Hongkong. 536555 .

[4]. Cambine, R. A., Ash, J. F. (1994). Medicinal Plants. British Journal Of Pharmacology, 2(34): 116-117.

[5]. Chois, S. Y., Chang J. P., Diary, B. D., Steol, G. H., Han,J. S. and Gallargher, M. B. (2005). Multiple Receptors Coupled To Phospholipase. Journal of Neuroscience, 25 (49): 433-446.

[6]. Daniels, T. F., Killinger, K. M., Michal, J. J., Wright, R. W and Jang, Z. I (2009). Lipoproteins, Cholesterol Homeostasis And Cardiac Health. International Journal of Biological Science, 15: 474-488.

[7]. Ochei, J. D and Kolhatkar, A.E (2007). Medical Laboratory Science $6^{\text {th }}$ Edition,

[8]. Mc Graw Hill, New Delhi, 190-198.

[9]. Renschler, H. E., Weicker, H. O and Baeyer V. H. (2005). The Upper Limit of Glucose Concentration in the Urine of Healthy Subjects. Deutsche Medizinische Wochenschrift, 45-50.

[10]. Sagara, C. R., Smith, W. J., Borgeat, P.A and FRitzpatric F. A. (2008). Lipoproteins and Membrane, Biochemistry of Lipids. 10 Edition, Elsevier Science Publishers, London. 118-161.

[11]. Stamler, J.O., Daciglus, M. L., Garsidectal, D. B., Dyer, A. R. Greenland, P. S and Newton. J. D. (2000). Relationship of Baseline Serum Cholesterol Levels In 3 Large Chords Of Younger Men To Long-Term Coronary, Cardiovascular And All-Cause Mortality And Longevity. Journal of the American Medical Association, 284: 311-318. 